\title{
ApPlication of a MultileVEl TECHNOLOGY ACCEPTANCE MANAGEMENT MODEL FOR EFFECTIVE TECHNOLOGY DEPLOYMENT
}

\author{
Gilbert Busolo, Lawrence Nderu and Kennedy Ogada \\ School of Computing and Information Technology, Department of Computing, Jomo \\ Kenyatta University of Agriculture and Technology, Nairobi, Kenya
}

\begin{abstract}
Effective deployment of a technology in an environment is the desire of many system developers. Positive uptake of a technology coupled with user acceptance is deemed as a key indicator towards technology acceptance. Knowledge is weighed as a strategic resource for any successful data driven decision making initiative. Institutions leverage on technological initiatives and tools to drive knowledge management (KM) initiatives that enhance quality service delivery and prudent data management. These initiatives provide the overall strategy for managing data resources. They make available knowledge organization tools and techniques while enabling regular updates. Derived benefits of positive deployment of a technological intervention are competency enhancement through gained knowledge, raised quality of service and promotion of healthy development of e-commerce. Successful and timely adoption of technological interventions through which knowledge management initiatives are deployed remains a key challenge to many organizations. This paper proposes the application of a wholesome multilevel technology acceptance management model towards effective technology deployment. The proposed model takes into account human, technological and organizational variables, which exist in a deployment environment. This model will be vital in driving early technology acceptance prediction and timely deployment of mitigation measures to deploy technological interventions successfully.
\end{abstract}

\section{KEYWORDS}

Model, Technology Acceptance, Knowledge, Management, Multilevel

\section{INTRODUCTION}

The realization that knowledge is a strategic resource for success of any organization's objectives and its subsequent adoption though a knowledge management system (KMS) is key. Driven by the desire of many if not all organizations to increase in quality of service, efficiency and optimized operations has led to development and integration of technological interventions. As technological generations change, new products whose aim is to enrich our living experience through automation, knowledge sharing, simplified and quality decision-making with feedback systems are continually developed. They have a rich digital repository for reference of the vast amount of historical, current and predictive information through machine leaning in the broader artificial intelligence concept. Uriarte (2008) defines knowledge management (KM) as the process through which individuals, organizations and even Governments generate value from their intellectual and knowledge-based assets. This process of knowledge creation is defined by stepwise and continuous evolution, not one that can be compactly planned and controlled. Emergent, motivation in which inspiration and pure change play is an important role in many situations. In addition, it has been widely accepted among scholars that social processes heavily influence organizational knowledge creation. 
Kwanya, Kiplang'at \& Wamukoya (2017) and supported by Fernandez \& Sabherwal (2010) state that the most vital resource of today's enterprise is the collective knowledge residing in the minds of an organization's employees, customers, and vendors. Successful management of this knowledge has many benefits to the business process. These benefits are not limited to leveraging on core business competencies, accelerating innovation and time-to-market while improving cycle times and decision-making. They also strengthen organizational commitment by helping to build sustainable competitive advantage in service delivery.

From a global perspective, Talisayon (2013) examines the role and success of a technological deployment. He notes that organizations worldwide face technological challenges as they continue to evolve into an automated work environment. This is pushed by paperwork and cost reduction mandates. All this is mirrored to requirements pointing towards increased workloads with fewer personnel and the rapid addition of electronic communication channels for use. Some of the common challenges that affect the service delivery sector include enhancing efficiencies across all agencies, improving accountability of resources and making data driven decisions. In addition, these technologies enhance collaboration and strategic partnerships with stakeholders, aid in capturing knowledge from an aging workforce as well as improving operational excellence. It is noteworthy to keep in mind that computerized knowledge management systems plays an imperative role in providing strategies and techniques to manage institutional content, making knowledge more accessible and usable. They provide the overall strategy to manage organizational data resources by making available knowledge organization tools and techniques. This aids in monitoring knowledge contents while making sure they are accessible and updated accordingly.

Among the derived benefits of knowledge management are enhanced competence, raising quality of service, and promotion of healthy development of e-commerce. Institutions and governments leverage on technology to provide long-term development blueprint for attaining global competitiveness. ICT as an enabler or foundation for socio economic transformation recognizes the role of science, technology and innovation in modern economy. Through this, new knowledge plays an essential role in boosting wealth creation, social welfare and international competiveness. However, this benefit is eroded through complexities experienced when users have challenges embracing new technologies. These efforts to embrace ICT tools in KM, encapsulating the desire to gain a competitive edge through data driven decision making for growth and development are at risk. Odinioha \& Chukwuma (2013) underscore the pivotal importance of quality information management in any organization. This is encouraged through focused acquisition, storage, dissemination and its utilization. It is evident that acquisition and application of a KMS does not guarantee its acceptance and effective use. According to Maier (2007), he states that even though ICT can be the enabling factor in a knowledge management initiative, there are limits to its use and the installation of a good platform does not always guarantee success. The sure assurance that any technological implementation is positively received and adopted is a hard question in the hearts and minds of many implementers. Great care is given to the product development life cycle through adoption of existing system development life cycle models. However, the greatest challenge and hindrance is acceptance of these technologies by the end users. Feedback in the public domain shows several initiatives that leverage on technology have fallen short notwithstanding the resources invested in their implementation.

This paper proposes application of a multilevel technology acceptance model for effective deployment of a technological intervention. The proposed model takes into account variables that exist in deployment environment. These are human, technological and organizational variables. This model is key in driving early technology acceptance prediction and timely deployment of 
mitigation measures for successful deployment of a technological intervention. This aims at shedding more light and demystifying the technology implementation and acceptance process. Secondly, the researchers proposes new constructs that can be considered in a technology implementation domain. These constructs mirror emerging trends and realities such as mandatory systems and e-government in a technology acceptance model.

\section{RESEARCH METHODOLOGY}

This process involves research and collection of data from several academic and scientific literature. Where possible, priority was given to sources that had published their data in the last five years. This is in cognizance to the fact that Information Communication Technology world rapidly changes and the foundations of this research are anchored on current pieces of information and practice. Constructs derived from the literature survey provided in-depth understanding of the technology acceptance process.

\subsection{Technology Adoption}

A decade old challenge in the technological world is gaining understanding as to why people accept or reject computer systems, as these are the basic infrastructure of any system. According to Davis, Bagozzi \& Warshaw (1989), this has proven to be one of the most challenging issues in information systems (IS) research. Investments in ICT-based tools that support planning, decision-making, and communication processes are inherently risky. Unlike clerical paperwork processing systems, these newer computing tools and systems often require managers and professionals to interact directly with hardware and software. However, end-users are sometimes unwilling to use available computer systems that, if used, would generate significant performance gains. The acceptance and use of information systems and information technology innovations has been a major concern for research and practice. Over the last several decades, a plethora of theoretical models have been proposed and used to examine technology acceptance and usage, Dwivendi, Rana, Jeyaraj, Clement \& Williams (2019). Forward-looking institutions and governments have identified ICT as an enabler and foundation for socio economic transformation and a tool to leverage on for success. In the quest of service delivery, key and focused ICT initiatives that leverage on acceptance of technological interventions are taking shape. In Kenya, adoption of technology as a service enabler is experienced at Huduma Centres. This is a egovernment initiative whose aim is to provide a one-stop shop service for government products to its citizens. Additionally other technological interventions like Kenya Revenue Authority (KRA) Integrated Tax Management System (ITMS) and E-Citizen platform enable the public access and pay for Government services online. All these technologies aim to enhance service delivery and provide a citizen centric one-stop non-stop model of service.

Hwang, Al-Arabiat \& Shin (2016) note that as new technologies, processes, procedures and systems infiltrate the world, research on potential adopters and acceptance of innovations receives attention from professionals and academic researchers. Developers of new technologies, senior management, and those responsible for managing the changes associated with the implementation of innovations are increasingly realizing that the lack of user acceptance can and most probably will lead to loss of money and resources. This greatly affects an organization's financial standing. It is evident that change creates a sense of uncertainty and lost control. Employees' resistance and lack of support are some of the most cited causes for failures associated with organizational change. This resistance represents a major barrier to organizational benefits derived from adoption of technological innovations. The most important concern for any manager is to ensure user buy-in through adoption of various techniques that ensure a positive attitude and outlook towards technology. This greatly affects its usage and success. Identification 
and adoption of correction measures that dissuade low automation levels and provide efficiency has led to various research initiatives on models that speak to the technology acceptance process. These aim to demystify complexities experienced when users have challenges embracing new technologies. This trend is observed as institutional systems around the world are incorporating technology as a core enabler towards growth, productivity and global competitiveness, Scherer, Siddiq \& Tondeur (2018).

Great strides in technological investments and interventions are evident. Lessons learnt from previous failures in acceptance and adoption of these technological interventions have turned the focus to technological models that deal with prediction of user behavior. This gives out data that informs the decision whether to adopt the technology, apply modifications to it or reject it in its totality, Aizstrauta, Ginters \& Eroles (2015). Discourse about benefits derived through adoption and acceptance of technology for any institution has been positively framed with a view that technology predominantly empowers societies. These are through savings on time, reduced costs and enhanced possibilities. Lowe, Dwivedi \& D'Alessandro (2019).Technology acceptance models strive towards deconstructing user attitude and behavior that consequently affect acceptance, use, performance and ultimately success or failure of any new technology.

\subsection{Technology Adoption Models}

The acceptance and increased utilization of technological innovations are crucially beneficial for both the service provider and user during the whole process of engagement, Gucin \& Berk (2015). Maier (2007) notes that success of any information system cannot be measured directly, but has to be assessed using a number of measures which are relevant for success. He notes that since the 70s, many authors have developed approaches to assess the success of an IS through several proposed variables, indicators and measures. As the researchers ponder on the time long challenge of technology rejection, this concern led to the study of several models that aim to explain computer acceptance and usage behavior. A technology adoption model explains the acceptance and consequent use of a technological intervention.

\subsubsection{Theory of Reasoned Action}

Theory of Reasoned Action (TRA) is an extensively studied model from the field of social psychology. It greatly concerns itself with the determinants of consciously intended behaviors. It deduces that a person's performance of a specified behavior is determined by his or her behavioral intent to perform the behavior and this is jointly determined by the person's attitude and subjective norm concerning the behavior as first studied by Davis, Bagozzi and Warshaw and cited in Lai (2017). In 1967, Martin Fishbein first introduced TRA, Ajzen \& Fishbein (1980) with an aim of bringing clarity to behavior of an individual in a voluntary environment. It picks beliefs, attitudes, intentions and behaviors as the main variables, articulating their relationship amongst one another in determining the end motivation that leads to an individual's action. Being a well-researched but general intention model, Lai (2017) that has been quite successful in the prediction and enlightenment of human behavior in a variety of domains, it should therefore be an appropriate choice model for reviewing computer usage determinants. Quite interestingly, TRA being a general model as shown in Figure 1 does not specify the beliefs that are operative for a particular behavior. To adopt it, researchers first identify beliefs that are salient for subjects regarding the behavior under investigation. Davis, Bagozzi \& Warshaw (1989) continue to clarify that the model proposes five to nine salient beliefs, gathered through free response interviews with representative members of the subject population. These beliefs are most frequently elicited from a representation of the sample population considered for use. 
Greene (2009) expounds that the development of TRA was to explain influences of several variables on behaviors that involve non-mandatory decision-making. Behaviors that are impulsive, habitual, or scripted are specifically excluded. TRA is not advised to be deployed where expounding of behaviors that are mandatory in nature like a frequent traveler getting through airport security but the theory is aptly applied to behaviors that the individual has some level of choice on the type of decision to be made. This aspect has been noted as a limitation to the theory as its focus and scope of application is on voluntary behavior.

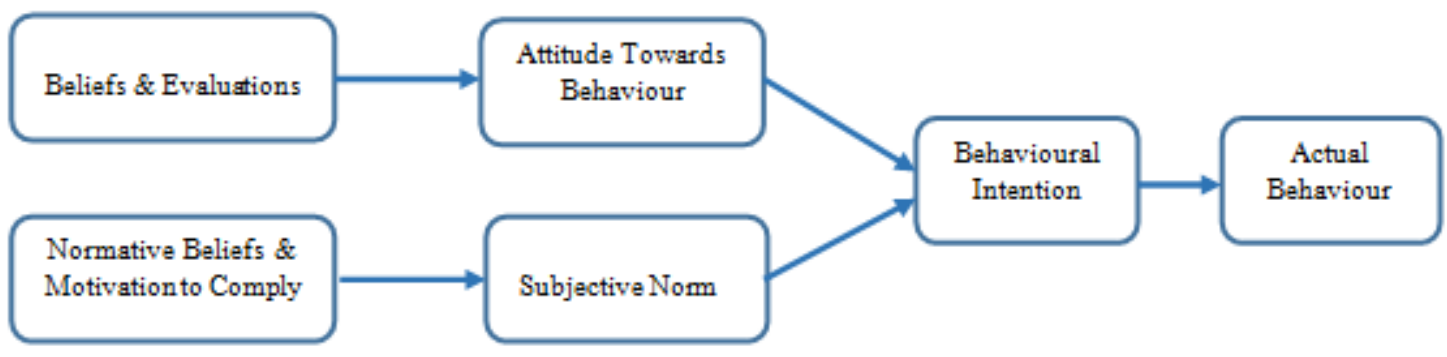

Figure 1: Theory of Reasoned Action (Lai, 2017)

Person's Performance $=$ Behavioral Intent $(\mathrm{BI})$

According to Greene (2009), Behavioral Intent (BI) that revolves around a person's plans, motivations or desires are the immediate forecaster of how one will behave. An individual's plan or activity revolves around an intention to accomplish something. A precursor of the proposed result is planning and accomplishing activities that make way for smooth execution of the main plan. A good analogy is the intent to further ones education is precipitated by the desire to increase in skill and consequently have a better life. When broken down, it entails looking for a good institution of higher learning, availing resources for the venture, prioritizing and rescheduling ones activities for the duration of the course, applying for the course among other foundational undertakings. The intent component greatly affects person's performance and choice of course as the theory can be applied in a KM environment to gauge the level of acceptance of a proposed technological intervention. As intentions can change depending on other conditions, it is a good component to tap on for positive behavior change, influencing an individual to undertake a positive action.

\section{Behavioral Intent $(\mathrm{BI})=$ Attitude $(\mathrm{A})$. Subjective Norm $(\mathrm{SN})$}

Greene concurs that intentions result from underlying attitudes and subjective norms therefore they are not independent. An attitude being a general orientation toward a behavior based on a variety of beliefs and evaluations is determined by identification of a set of relevant beliefs, measuring their strength or certainty of these beliefs, and measuring their evaluation. Then the measures are summed together resulting in an attitude measurement. Attitudes are specific to performing a particular behavior. To determine an attitude, belief strength and evaluation are empirically weighted for a specific behavior and group before they are added together. These relative weights are discovered through surveys of individuals in the target audience about a behavior. The importance of attitudes, as determined through surveys, is helpful in designing intervention drives to address the component that best predicts behavioral intentions. Subjective norms being the social component of behavioral intentions are composed of normative beliefs that are influenced by the view of other people concerning that behavior and the drive to comply with the directive or task at hand. Depending on the issue at hand, influence may be heavier from one quarter than from another quarter hence influencing the direction of action of the person. The 
pressure to be in good standing with a group of people or a certain individual has great impact in a decision.

$$
\text { Attitude towards Behavior (A) }=\sum \text { Salient Beliefs (b1). Evaluations (e1) }
$$

Salient behavioral beliefs held to determine the attitude toward the behavior and the envisioned consequences of performing that behavior. Salient normative beliefs (beliefs about the views of significant others) are held to determine subjective norm. Salient control beliefs (beliefs about factors that may facilitate or impede performance of the behavior) are assumed to determine perceived behavioral control. Salient beliefs are those that first come to an individual's mind as repercussions of performing a certain act or engaging in a specific activity, Sutton et al. (2003). The behavioral beliefs can be either positive or negative. An individual can believe that technology will ease the process of doing work but may also believe that computer use will affect his eyesight or even increase chances of getting cancer. Evaluations are appraisals taken by the individual attached to a behavioral outcome or attribute. This includes negative or positive views about the behavior and greatly contributes to attitude along with behavioral beliefs.

$$
\text { Subjective Norm }(\mathrm{SN})=\sum \text { Normative Beliefs (nb1). Motivation to Comply (mc1) }
$$

Davis, Bagozzi and Warshaw (1989) and Lai (2017) agree that an individual's subjective norm is determined by a multiplicative function of his or her normative beliefs that are guided by perceived expectations of specific referent individuals or groups. This is greatly determined by social pressure and affects his or her motivation to comply with these expectations. This is influenced by the presumed perception of what others think of the issue at hand. Fishbein and Ajzen (1975) rank TRA as a general model as it does not specify the belief parameters that are operative for a particular behavior. In its application, researchers have first to undertake the task of identifying the beliefs that are outstanding for subjects regarding the behavior under investigation. They do recommend researchers to identify and engage with a minimum of five and a maximum of nine salient beliefs using free response interviews to elicit data with representative members of the subject population. It is recommended that the beliefs most commonly elucidated from the sample population be used. During research and application of TRA, its main drawbacks arise from lack of addressing the role of habit, cognitive deliberation and usage voluntariness, Taherdoost (2018).

\subsubsection{Technology Acceptance Model}

Technology Acceptance Model (TAM) is a less general adaptation of TRA introduced in 1986 by Davis and heavily researched in this day and age, Hwang, Al-Arabiat \& Shin (2016). It has a specific application area for modelling user acceptance in an information systems environment as an early stage user acceptance tool. This model is envisaged to provide an understanding of the parameters that influence computer acceptance that are general, capable of explaining user behavior across a broad range of end-user computing technologies and user populations, while at the same time being both parsimonious and theoretically justified. According to Davis, Bagozzi \& Warshaw (1989) and Hwang et al. (2016), TAM posits that two particular beliefs, perceived usefulness and perceived ease of use are of primary relevance for computer acceptance behaviors as shown in Figure 2 below. 


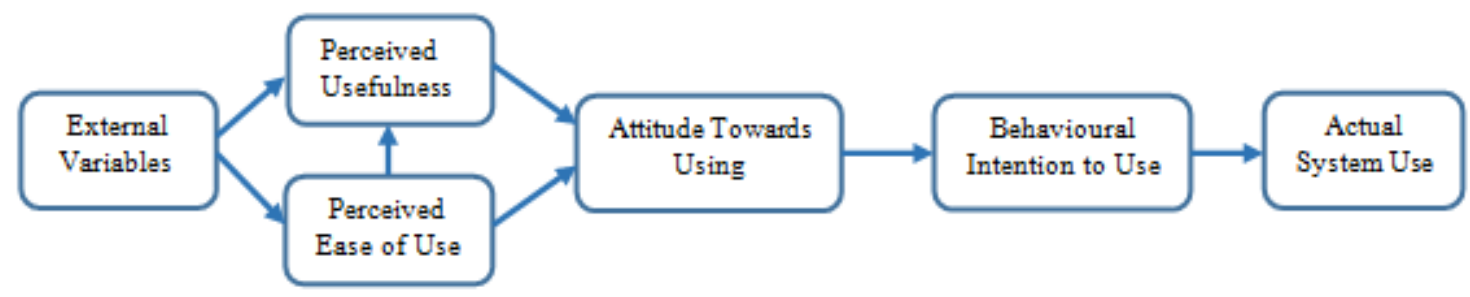

Figure 2: Technology Acceptance Model (Hwang, Al-Arabiat \& Shin, 2016)

TAM model revolves around these two parameters to determine attitude towards using a technological intervention. This is underscored by Scherer et al. (2018) pointing out that perceived usefulness and perceived ease of use are considered as the key variables of TAM as they generally describe the outcomes when applied in a technological environment. These are perceived usefulness and perceived ease of use as the main determinants towards technological acceptance behavior as illustrated below.

$$
\text { Attitude }(\mathrm{A})=\text { Perceived Usefulness }(\mathrm{U})+\text { Perceived Ease of Use (E) }
$$

Davis, Bagozzi \& Warshaw (1989) defines the two major TAM identifiers, Perceived Usefulness (U) as the prospective user's subjective probability that using a specific application system will increase his or her job performance within an organizational context. Perceived Ease of Use (EOU) refers to the degree to which the prospective user expects the target system to be free of effort. The Perceived Usefulness and Ease of Use are intertwined and affect each other because when a user positively identifies and feels that a system is easy to use to achieve the set organizational goals, then the system becomes useful for them, hence having a positive attitude towards technology and influencing behavior.

$$
\text { Behavioral Intention to Use }(\mathrm{BI})=\text { Attitude towards Using (A) + Perceived Usefulness (U) }
$$

The relationship between Attitude (A) and Behavioral Intention (BI) commonly referred to as The A-BI relationship implies that when all other factors are constant, system users will form an intention to use a technological intervention, which they perceive to have a positive effect on them. Attitude is recognized as a major factor that influences technology acceptance or rejection during deployment and subsequent use. The U-BI relationship between Perceived Usefulness (U) and Behavioral Intention (BI) is grounded on the idea that in an organization setting, users form an intention on behavior that they believe when undertaken, will generally increase their work performance over any other positive or negative perception evoked. The base reason being that achieving good results in such an environment like a work environment is instrumental to acquiring other rewards that are extrinsic to the content of the work itself, such as better pay or a higher grade through promotions.

\section{Perceived Usefulness $(\mathrm{U})=$ Perceived Ease of Use $(\mathrm{E})+$ External Variables}

Any technological intervention deployed that offers an easy to use interface, defined and logical workflows and systems that enable the user to accomplish more work with less effort is perceived as easier to use. One that outputs high quality graphs with detailed precision scores better. This enables improved performance when leveraging on technology and directly affects perceived usefulness. Additional features that ease the interaction between the system functionalities and the user while achieving the set system objectives enhance usability. When the external variables in the operating environment are conducive, optimally supporting technological interventions, the expected output will be quite positive. External factors in the operating environment that impinge 
on the optimum working atmosphere and environment hinder the perceived usefulness of that technology and by large the user may form a negative attitude towards technology.

\section{Perceived Ease of Use $(\mathrm{E})=$ External Variables}

There is a direct correlation between Perceived Ease of Use (E) and External Variables that are present in the deployment environment. External Parameters like experience working on computer systems, years spent on automated systems, exposure to technology among others greatly influence the user's perspective on how easy or difficult it is to use the system. A system which is positively evaluated is more acceptable and useable, Hwang et al. (2016). Davis (1993) encourages more research on the role of additional TAM variables for the model to be more responsive to technological environments that have more parameters that greatly influence the acceptance and deployment of technology. Parameters like choice in a mandatory environment is a key variable that influences attitude as the user has to interface with the system for daily work irrespective of his attitude towards it. One of the greatest drawback of TAM is its inability to inform the implementation process, Hwang et al. (2016).It leans heavily towards user acceptance, leaving out system designers and project implementers. For TAM to continue being relevant to modelling user interactions with technology, researchers are called to consider it as a basic model that offers the benefit and flexibility of integrating extended and contextualized motivational influences and user behaviors based on emerging realities in contemporary technological environments, Lim (2018). For clarity in understanding and adoption of TAM, the model should be augmented with new variables that are context specific to the application environment and mirrored with the times, Lowe et al. (2019) to provide more consistent prediction of system use, Taherdoost (2018).

\subsubsection{Task Technology Fit Model}

Goodhue and Thompson as cited by Lai (2017) ponders on the linkage between information technology adoption and its corresponding effect on individual performance on a given a task. The Task Technology Fit Model (TTF) as shown in Figure 3 below underscores the degree to which a technology deployment assists an individual in performing his portfolio of tasks. An important factor to note with TTF is that there is little explicit recognition that more utilization of a system will not necessarily lead to higher performance. Utilization of a poor information system will not improve an individual's performance. TTF draws its constructs from two assertions; utilization of a technology and the leveraged technology should be a good fit to the task deployed as predictors of performance.

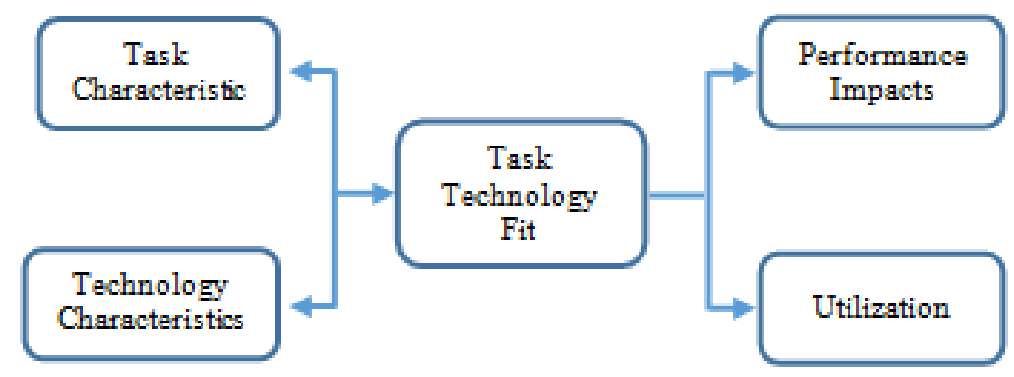

Figure 3: Task Technology Fit Model (Lai, 2017)

Utilization of a technological intervention is based on human perspective and other situational factors like attitude, behavior, perceived satisfaction and social norm. These factors affect the initial technological perspective when a system is introduced and continue having weight on its 
repeated utilization. From this theory, it is implied that increased utilization of a system having positive human outlook impacts positively on its performance rating. When a technological intervention offers features that are just right for the purposed task, the user will feel that this is the technological tool of choice, hence the fit. This perceived sense of a tool that eases the task load through features that break down the task into doable subtasks while simplifying the whole process optimally leads to better utilization and performance. The level of technological fit is a strong predictor of better performance. Further research on the TTF model by Goodhue \& Thompson (1995) led to Technology to Performance Chain theory (TPC) as shown in Figure 4. This is a more individualized model that looks at both the technology and its utilization in relation to its relevance to the perceived task. Its underlying mantra is that technologies must be utilized and fit the task they support to have a performance impact. It provides clear relationship on the technological, user tasks and utilization variables as they relate towards progressive or retrogressive performance. It is important to note that in as much individuals embrace technological tools to accomplish given tasks, the individual's characteristics could greatly influence how well the technological utilization will be. Some of these individual characteristics are motivation, prior training and experience with technological interventions.

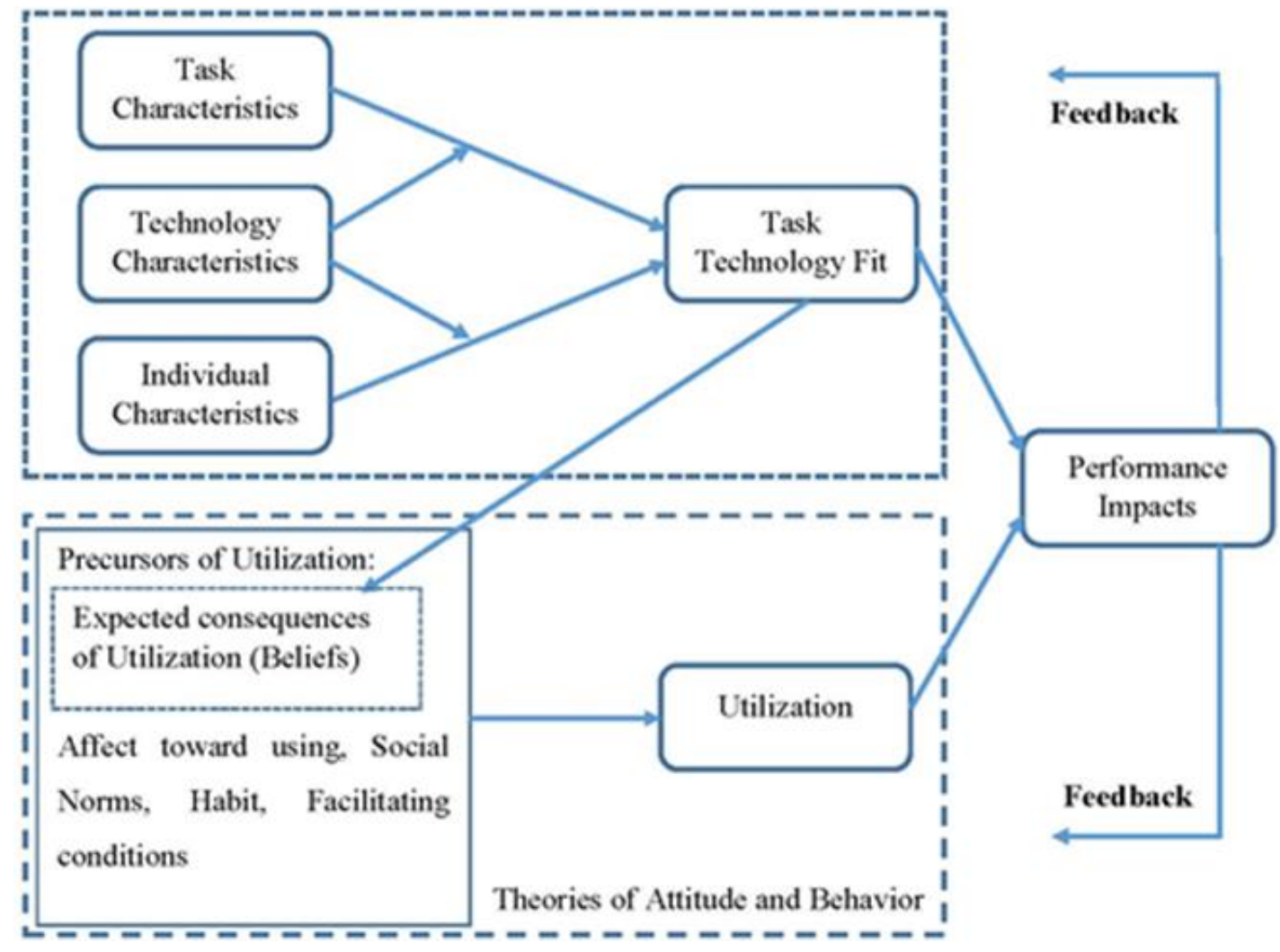

Figure 4. Technology to Performance Chain Model (Goodhue and Thompson, 1995)

\subsubsection{Unified Theory of Acceptance and Use of Technology}

Unified Theory of Acceptance and Use of Technology (UTAUT) technology acceptance model was formulated out of the gaps experienced with the use of several technology acceptance models. Venkatesh, Morris, Davis \& Davis (2003) comprehensively reviewed eight technology acceptance models and formulated a unified model as shown in Figure 5 after data synthesis, whose aim was to integrate elements across the eight models while addressing their shortcomings. The eight models reviewed were the technology acceptance model by Davis 
(1989), the theory of reasoned action by Fishben \& Ajzen (1975), the motivational model by Davis, Bagozzi \& Warshaw (1992). In addition, the theory of planned behavior by Taylor \& Todd (1995), the model of PC utilization by Thompson, Higgins \& Howell (1991), the innovation diffusion theory by Moore \& Benbasat (1991), the social cognitive theory by Compeau \& Higgins (1995) and a combined version of technology acceptance model (TAM) and theory of planned behavior were reviewed. They used data drawn from four different organizations over a period of six months and conducted their research based on three points of measurement. This research was borne out of an observation that several underlying concepts drawn from technology acceptance theories were inherently comparable, Zhou, Marfo, Antwi, Antwi, Kachie \& Wireko (2019).

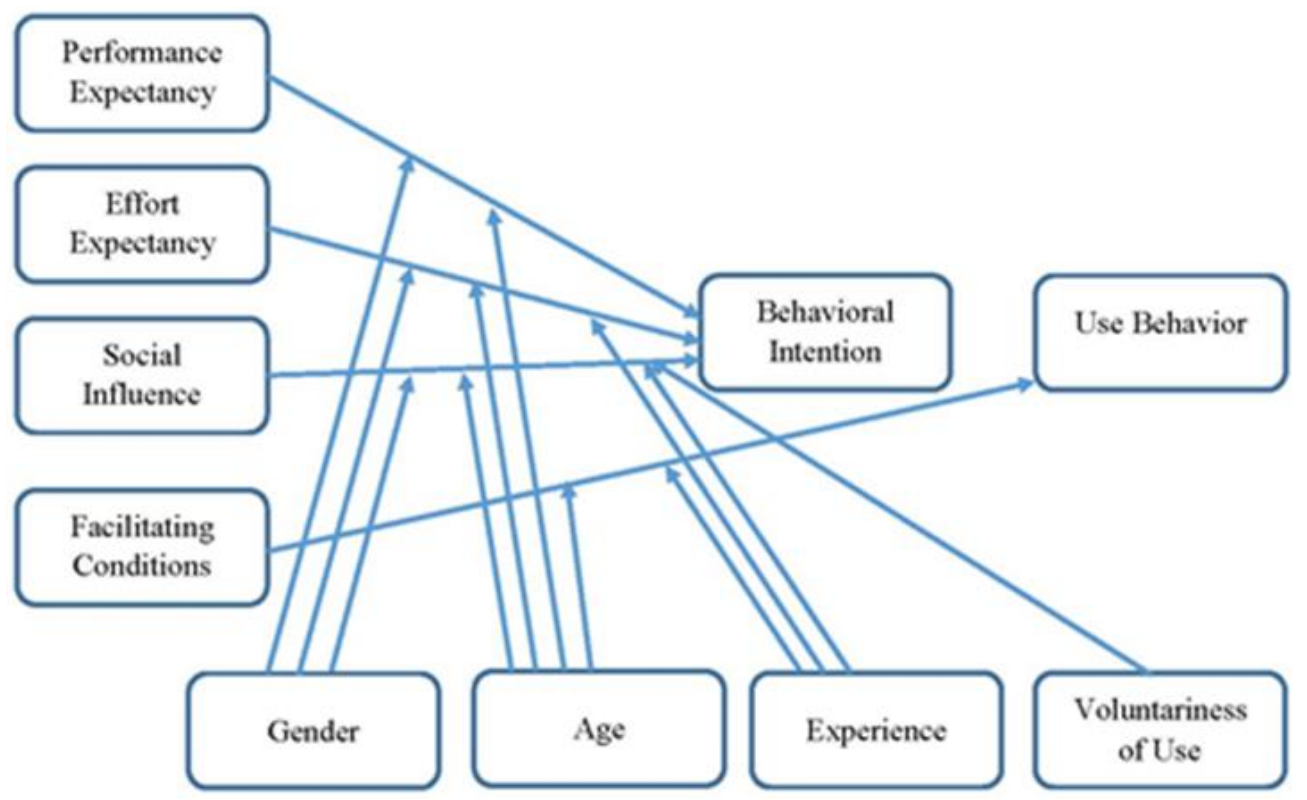

Figure 5: UTAUT Research Model (Venkatesh, Morris, Davis \& Davis 2003)

The eight choice models were adaptable to only between 17 percent and 53 percent variance in the results concerning user intentions on their use of information technology, Venkatesh et. al. (2003). From these findings, the proposed UTAUT technology acceptance model was applied to the original data and fared better, outperforming the eight models with adaptability of 69 percent. Four constructs stood out and were earmarked as indicators that were direct determinants towards technology acceptance. These were performance expectancy, effort expectancy, social influence and facilitating conditions. Venkatesh et. al. (2003) in their research concluded that attitude towards using technology; self-efficacy and anxiety did not meet the threshold to be considered as main determinants towards intention of using a technological intervention. The UTAUT research model was as shown in figure 5 above.

Dwivedi et al. (2019) and Venkatesh et al. (2003) expound performance expectancy as the degree or weight to which an individual believes that using a particular technological intervention will enable the user attain gains in their work performance and subsequently, their output. The term performance expectancy is drawn from the amalgamation of five factors that were weighed in the formation of perceived ease of use during research on technology acceptance model. These five constructs are external motivation, job fit, relative advantage as well as outcome expectancy, Venkatesh \& Davis (2000). Noted as a positive factor towards technology acceptance and use, performance expectancy construct has received a lot of attention and research, Hamzat \& Mabawonku (2018). 
Effort Expectancy is the level of ease experienced when a technology is in use, Alam, Hu \& Gani (2019). A technology whose effort expectancy is good exhibits ease of use tendencies. Users feel drawn to such system and the observed percentage of acceptance to such systems is usually high making adaptation to these technologies easier. This construct can be applied in environments that exhibit voluntary and also mandatory tendencies. Some of the techniques that effort expectancy can be achieved is through easy to use interfaces and user involvement during technology development and deployment, to the level where the user feels familiar with the technology and believes that the system is easy to use to deliver the set objectives. Effort expectancy is derived from three constructs: perceived ease of use, complexity and ease of use, Alam, Hu \& Gani (2019) and Venkatesh et. al. (2003).

Social influence is explained as the degree at which a user believes that the technology adapted is easy to use based on the views of others concerning that technology. Venkatesh et. al. (2003) expounds it as the degree to which a user perceives that others who hold an important role believe that he or she should use the new system. This construct is directly fed from subjective norm, social factors and perceived image derived when one uses the new technology. This construct generally is adaptable when a technology is deployed in mandatory conditions and is experienced due to the fact that the user has not yet had any or minimal interaction with the system. Consequently, his views are based on other people's views, who may have had a higher level of interaction with it. Normally, this position changes when the user gets to use the system and from the personal interaction, a solid view of the system is derived.

The degree to which a user believes that there exist enough organizational and technical infrastructure to support the use of the new technology is referred to as facilitating condition, Alam, Hu \& Gani (2019) and Venkatesh et. al. (2003). During development and deployment of any system, it is prudent to consider the environmental and technological system use needs for removing any obstacles that may cause technology rejection. Deployment of a good technological intervention in an environment that is not ready or responsive to its adoption and optimum use is already a recipe for failure. As the important system development factors are dealt with, a keen look should be given to the environmental and technological optimal system use needs for successful technological deployment.

Alam, Hu \& Gani (2019) underscore the pivotal need for high reliability and maintainability of any technological intervention during its lifetime. This is an important factor of any system and in the extended UTAUT model, it comes out clearly as perceived reliability which is critical to user acceptance, satisfaction and usage. The costs associated with acquisition, use and maintenance of technological interventions is a pivotal factor to consider when considering any system. Growing needs and changes in the operational environment call for changes in the structure of any system. This may be new laws governing the use of the technology, changed business model or just upgrades for increased dependability, safety and quality of service call for periodic maintenance and updates. Users therefore are quite aware of these needs and their corresponding financial effect on the overall budget for maintenance. In this regard, the extended UTAUT model includes price value and perceived reliability as key constructs in addition to performance expectancy, effort expectancy, social influence and facilitating condition in its matrix.

\subsection{Findings of the Study}

The researchers summarizes the choice models as shown in Table 1 below: 
Table 1: Choice Models Comparison

\begin{tabular}{|c|c|c|c|}
\hline \multicolumn{4}{|c|}{ Summary Findings } \\
\hline Construct & Application Area & Strengths & Limitations \\
\hline \multicolumn{4}{|c|}{ Theory of Reasoned Action (TRA) } \\
\hline $\begin{array}{l}\text { a) Beliefs } \\
\text { b) Attitudes } \\
\text { c) Intentions } \\
\text { d) Behaviors } \\
\text { e) Subjective Norm }\end{array}$ & $\begin{array}{l}\text { Social Psychology. } \\
\text { Used to determine } \\
\text { consciously } \\
\text { intended behaviors }\end{array}$ & $\begin{array}{l}\text { Extensively } \\
\text { studied model on } \\
\text { consciously } \\
\text { intended } \\
\text { behaviors }\end{array}$ & $\begin{array}{l}\text { a) Difficult to implement in } \\
\text { environments where choice is } \\
\text { limited. } \\
\text { b) Sufficiency of attitudes and } \\
\text { subjective norm to clearly predict } \\
\text { behaviors. } \\
\text { c) Does not address role of habit. } \\
\text { d) Does not address role of } \\
\text { cognitive deliberation }\end{array}$ \\
\hline \multicolumn{4}{|c|}{ Technology Acceptance Model (TAM) } \\
\hline $\begin{array}{l}\text { a) Perceived } \\
\text { usefulness } \\
\text { b) Perceived ease of } \\
\text { use }\end{array}$ & $\begin{array}{l}\text { Modelling user } \\
\text { acceptance in and } \\
\text { information } \\
\text { systems } \\
\text { environment }\end{array}$ & $\begin{array}{l}\text { Widely applied } \\
\text { model in } \\
\text { information } \\
\text { technology } \\
\text { environments } \\
\text { with several } \\
\text { adopted variations } \\
\text { to it }\end{array}$ & $\begin{array}{l}\text { a) The two variables do not aptly } \\
\text { represent and model current } \\
\text { technological environments. } \\
\text { b) Focuses more on user, not } \\
\text { operating environment } \\
\text { c) No variable represents design } \\
\text { process or informs } \\
\text { implementation phases }\end{array}$ \\
\hline \multicolumn{4}{|c|}{ Task Technology Fit (TTF) } \\
\hline $\begin{array}{l}\text { a) Utilization of a } \\
\text { technology } \\
\text { b) Technology Fit }\end{array}$ & $\begin{array}{l}\text { Technological } \\
\text { environment }\end{array}$ & $\begin{array}{l}\text { Adaptable to new } \\
\text { products already } \\
\text { in the market }\end{array}$ & $\begin{array}{l}\text { a) Difficult to implement in } \\
\text { environments where choice is } \\
\text { limited. } \\
\text { b) Utilization of a system with } \\
\text { low TTF will not increase } \\
\text { performance. }\end{array}$ \\
\hline \multicolumn{4}{|c|}{ Unified Theory of Acceptance and Use of Technology (UTAUT) } \\
\hline $\begin{array}{l}\text { a) Performance } \\
\text { Expectancy } \\
\text { b) Effort Expectancy } \\
\text { c) Social Influence } \\
\text { d) Facilitating } \\
\text { Conditions }\end{array}$ & $\begin{array}{l}\text { Technological } \\
\text { environment }\end{array}$ & $\begin{array}{l}\text { Uses moderators } \\
\text { of gender, age, } \\
\text { experience and } \\
\text { voluntariness of } \\
\text { use that can be } \\
\text { adjusted } \\
\text { according to } \\
\text { environment. }\end{array}$ & $\begin{array}{l}\text { a) Scales used to measure the } \\
\text { constructs are not conclusive. }\end{array}$ \\
\hline
\end{tabular}

From the literature review, it is evident that technology acceptance models mostly focus on one dimension of implementation. We can see that greater focus has been given only to the user, the proposed technology or the task to be automated. In addition, most system developers leverage on the software development lifecycle process that primarily focusses only on the software product. These gaps informed the development of a multilevel technology acceptance management model that encompasses more variables that exist in a deployment environment. Quite noteworthy, the deployment of a technological intervention into an environment that is not wholesomely ready erodes the anticipated gains.

The objective of this research was to propose the application of a multilevel technology acceptance management model that takes into account human, technological and organizational variables. Review of existing models and their limitations aim to provide deeper reason for research on a model that mitigates the identified limitations. Identification and application of new constructs that exist in a deployment environment is pivotal to this research as it brings a better understanding of the deployment environment. Successful deployment of technologies through 
International Journal of Computer Science \& Information Technology (IJCSIT) Vol 13, No 1, February 2021

early technology acceptance prediction and timely deployment of mitigation measures is the desire of many organizations. The proposed model that incorporates new constructs aim at explaining technology acceptance of emerging technologies such as e-government, internet-ofthings, e-board and Enterprise Resource Planning Systems. This is grounded in the need for a comprehensive understanding of IT adoption and factors that determine its success or failure.

\subsection{Proposed Multilevel Technology Acceptance Management Model}

Derived from analyzing the choice models while mirroring this knowledge to the current deployment environment, the researchers propose a multilevel technology acceptance management model as illustrated in Figure 6. Every system project manager would love to be able to predict whether the technological deployment will be acceptable to the envisioned users. Davis, Bagozzi \& Warshaw (1989) laid a foundation to this discussion by recommending that a model should also be in a position to diagnose the base reasons why a proposed system may not be fully acceptable to the users. It should also provide an opportunity for corrective action to be taken thus increasing acceptability of a technological intervention. This will increase business impact, saving time and resources that would otherwise go to waste deploying and supporting a system that is unproductive and not supportive to the business goals.

Taherdoost (2018) explains that although a number of models and frameworks have been developed, explaining user adoption or rejection of new technological interventions needs more than one theoretical approach for a wholesome understanding. This creates a cumbersome process and consequently, need for a model that when applied, encompasses most of the possible variables that exists in a deployment environment is key. The apparent need for further research into models that provide an ever-richer understanding of technology adoption is key. This is proposed through consideration of constructs that relate to each other with representation from the human, technological and organizational perspective. The proposed model aims to bring more clarity to technological deployment process through assessing key parameters derived from the deployment environment. It groups the key variables into three main categories:

i. Human variables

ii. Technological variables

iii. Organizational variables

It is envisioned that this will bring understanding and inform the technology deployment process on the parameters and key variables that need to be focused on for technology acceptance. The proposed variables with their corresponding factors are synthesized into a multilevel knowledge management acceptance model that forms a foundation for the study. The illustrated model below depicts the three multilevel dimensions towards technology acceptance. 


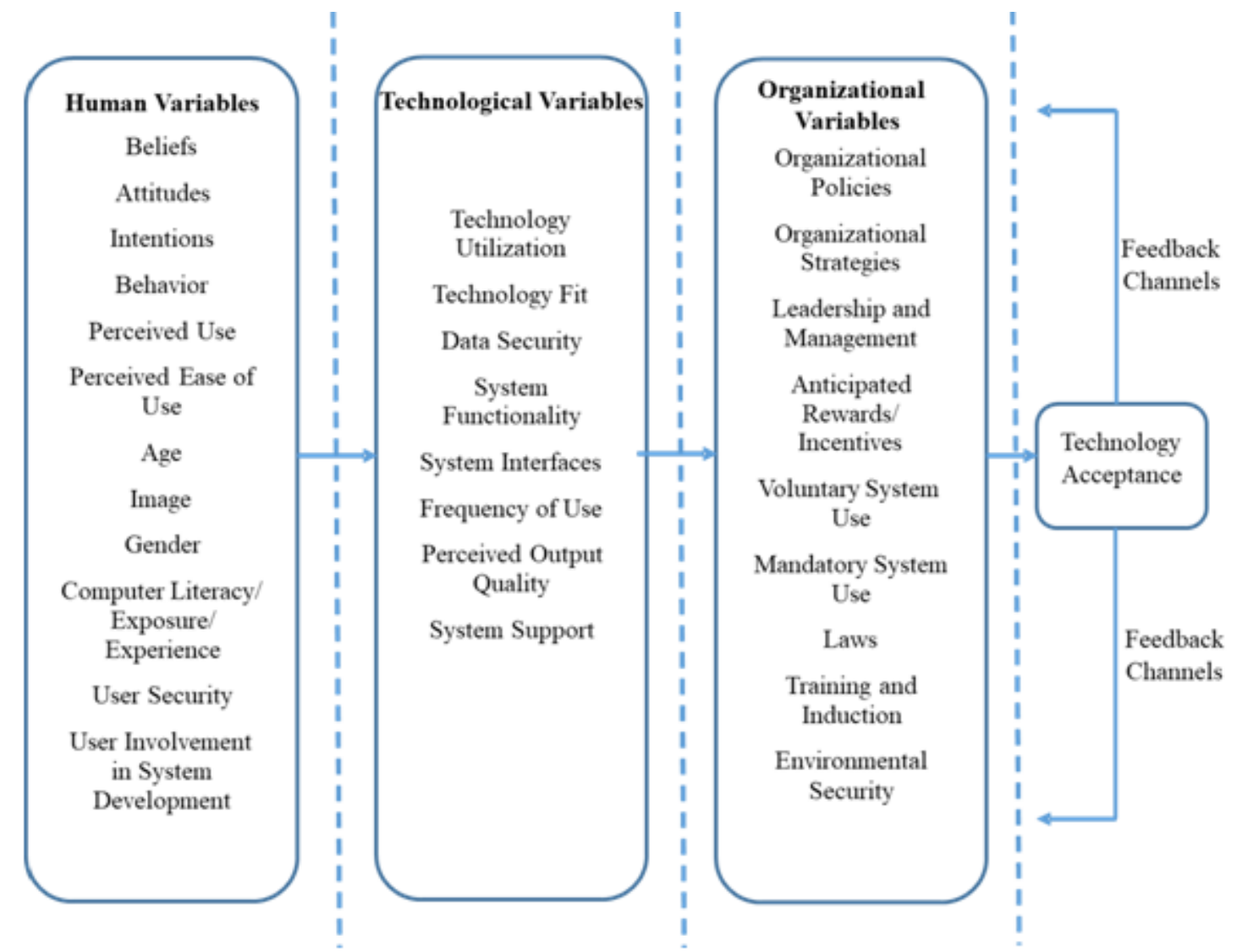

Figure 6. Proposed Multilevel Technology Acceptance Management Model

It has been observed that the application of variables to TAM that are dependent to the application environment address its limitations and potentially confirm its robustness and generalizability, Fayad \& Paper (2015).

\subsubsection{Human Variables}

Research shows that the level of end-user satisfaction with an information technology intervention has widely been accepted as an indicator of IT success. This is according to Mahmood, Gemoets \& Jacquez (1999). These variables are human related characteristics such as beliefs, attitudes, intentions, perceived ease of use and perceived use that directly have emotional impact the user's perceived value of the system. Variables such as age of the user, their gender and image have a direct bearing on where the individual places himself in terms of personal relevance to technology. Computer literacy and exposure to technology, perceived personal security from any technology related harm, user involvement in the system development process brings about a sense of ownership to the proposed technological deployment, the user feels they have a part to play towards technological success and are more inclined towards technology use. User acceptance and satisfaction, a key ingredient in technology adoption starts at the point where the individual's perception concerning technology is positive and its perceived value is high.

\subsubsection{Technological Variables}

Technology related variables encompass the technological need on the ground and the solutions availed through a technological intervention. Deployments of technological solutions increase 
day by day as the world finds an easy partner to a myriad of challenges in technology. Being enlightened on the antecedents of technology use early enough during the development and deployment process informs key project steps and is a recipe for success. In as much as the world recognizes technological inventions as a sure bet on easing many processes, that are characterized as loads, the level of acceptance of these interventions is quite wanting and a major concern to product developers and solution providers. When a user perceives technology as a positive tool in their sphere of operation, he will evaluate the technological capabilities and risks associated with its adoption. Variables such as technology utilization in accomplishing the laid objectives, technology fit to the projected tasks, system functionality to accomplish the desired procedures endear a user and underscore the usefulness of technology. System interfaces that are easier to navigate to achieve the set goals increase system utilization. Perceived and actual period that the system will be in use plays an important factor in its acceptance.

A balance should be sought on time and frequency of use for maximum gains. As all systems have an input and output, the quality of system output should reflect the effort infused in the input process. A clear, concise, comprehendible and quality output should be the target for any technological intervention. The data in use should be secure from instances that may compromise its quality. The constant worry of any organization when deploying any technological intervention is the availability of technical support for the product over a period of time. This includes but is not limited to availability of periodic updates, upgrades and support when the need arises. Any technological system that does not have an established support base is destined to fail and its level of acceptance may be below par.

\subsubsection{Organizational Variables}

Every technology operates in its required environment. The process of deploying technology may be successfully controlled with key acceptance variables dealt with early enough to ensure all-out acceptance and business gains derived from it. During deployment and operations, other external factors that may be within or beyond the scope of management may change influencing the technology adopted either positively or may negate the gains derived through its adoption. Organizational policies should be friendly to technology adoption through decisive policy statements that support adoption and deployment of relevant technologies that aid in fulfilling the goals of any institution. These should be enablers that give flesh to fulfilling organizational strategies and goals. Laws governing the use of any technology should be well balanced to accord users an equilibrium, gaining the benefits of technological adoption while shielding them from instances of abuse, harm and insecurity. Top management attitude towards technology dictates how far technology adoption and use in any organization goes. Formulation of strategies and policies that encourage technology adoption and harness its use in organizational procedures is a recipe for success. Set incentives and rewards to users who leverage on technology to accomplish tasks increases its adoption and frequent use.

Laws set and reviewed by the legislature should be void of collisions with adoption of technology, but rather encourage its use. Regulations that clearly spell out procedures like conveyance should be amended to encompass use of technology as an enabler to quality service delivery. Yearly, the government requires all of its citizenry with personal identification numbers to file tax returns. Great efforts through capacity building campaigns and awareness is vigorously conducted in the social space but still the response to this exercise is below par with unmet targets. The mandatory or voluntary nature to the adoption and use of any system directly influences the user perception towards it. Induction and training on use of technology helps bridge technology related fear and enables the user appreciate its use in achieving the set goals. All these deployments should be in a controlled environment and should not cause any harm to 
its users or environment. Any perceived threats should be addressed in a sober, informative and inclusive manner to the benefit of its adoption. The way an organization handles its internal and external (environmental) variables reflect on its readiness on the adaption of technology. How a country or organization handles these external variables directly affect the perception towards technology adoption and subsequent use. Every system has users, the system itself has some technical capabilities and all these exist in an environment that the user cannot exclusively control. It is pivotal for any successful technological adoption, these three variables be keenly appreciated as they directly affect human perception towards technology and its successful use.

The model inculcates feedback as a key element in adoption, successful acceptance, usage, and further upgrades that may be undertaken for making the technological intervention more responsive to user needs. Feedback mechanism may also influence the variables in the three groupings as each deployment environment has unique users, deployed technology and external variables and therefore is not exhaustive. This model is more suited for a technological deployment environment.

\subsection{Application of the Multilevel Technology Acceptance Management Model}

The desire for a successful technological deployment is a major concern to many technology implementers. This has led to development of a model that provides new variables that span beyond the human focus of the reviewed models. Data derived through application of this multilevel technology acceptance management model illuminates the deployment process through data driven decision-making efforts. Flagging out key areas that may need focus and greater attention for a fruitful deployment is made possible through adoption of independent variables for a more inclusive and comprehensive evaluation when testing the dependent variable. The developed model aims to provide a better understanding of the deployment environment and candidate system through variables that exist in a deployment environment. This assures of a wholesome deployment experience. Great focus is given not only to the users or to the prospective software tool, but also to all factors that exist in that environment that may make or break the deployment process. We all aim to get it right the first time when implementing a technological deployment and this model provides a clear path to that.

In addition, this model stimulates more research on technology adoption and a drive for deeper understanding of relationships among variables, technologies, users and their technological environments.

\subsection{Further Research}

As the world continues to embrace technology, different technological application areas exist. These deployments sometimes are not successful due to inconclusive and comprehensive data driven understanding of the pivotal variables that exist in that environment. This calls for further research and validation of the proposed model with its constructs for a robust and more inclusive technological acceptance model. This may include specific application environments like health and education as this may bring rise to different constructs that are technological environmentspecific while maintaining a wholesome outlook to the technology acceptance process.

\section{Conclusions}

Institutions and individuals desire to get it right the first time when implementing a technological deployment. This desire led the researchers to propose a model that provides new variables that span beyond the human focus of the reviewed models. The proposed model when applied to a technological intervention environment hopes to provide a better understanding of the 
International Journal of Computer Science \& Information Technology (IJCSIT) Vol 13, No 1, February 2021

deployment environment and candidate system. Data derived from the proposed model aims to illuminate the adoption path through data driven decision-making efforts. The proposed model adopts independent variables for a more inclusive and comprehensive evaluation when testing the dependent variable. In addition, this stimulates research and a drive for deeper understanding of user relationships with newer technologies in their technological environments.

\section{REFERENCES}

[1] Uriarte F. A (2008). Introduction to Knowledge Management, Jakarta, Asean Foundation.

[2] Kwanya T. Kiplang'at J. \& Wamukoya J (2017). Emerging Trends in Information and Knowledge Management, Eldoret, Moi University Press.

[3] Fernandez, I.B \& Sabherwal, R (2010). Knowledge Management systems and Processes, New York, Armonk Publishers.

[4] Talisayon S. (2013). Knowledge Management for the Public Sector, Tokyo, Asian Productivity Organization.

[5] Odinioha, G.J and Chukwuma, O.L (2013). The International Journal of Management, Volume 2, Issue 3, Port Harcourt, Wiley-Blackwell Publishers.

[6] Maier R. (2007). Knowledge Management Systems, Third Edition, Innsbruck, Springer. DOI 10.1007/978-3-540-71408-8.

[7] Davis F., Bagozzi R. \& Warshaw P. (1989). User Acceptance of Computer Technology: A Comparison of Two Theoretical Models, Michigan, Ann Arbor, Institute of Management Science.

[8] Dwivendi Y. K, Rana P.N. Jeyaraj A., Clement M. \& Williams M. D. (2019). Re-examining the Unified Theory of Acceptance and Use of Technology (UTAUT): Towards a Revised Theoretical Model. 21, 719-734. DOI 10.1007/s10796-017-9774-y.

[9] Hwang, Y. Al-Arabiat M. \& Shin, D.H (2016). Understanding Technology Acceptance in a Mandatory Environment, UK, Sage Publishers.

[10] Scherer R., Siddiq F. \& Tondeur J. (2018). The Technology Acceptance Model (TAM): A Metaanalytic Structural Equation Modelling Approach to Explaining Teachers' Adoption of Digital Technology in Education: Norway, Elsevier.

[11] Aizstrauta D., Ginters E. \& Eroles M. P (2015). Applying Theory of Diffussion of Innovations to Evaluate Technology Acceptance and Sustainability. 43. 69-77. DOI 10.1016/j.procs.2014.12.010.

[12] Lowe B., Dwivedi Y. \& D'Alessandro S. (2019). Consumers and Technology in a Changing World. Retrieved 28 December, 2019 from https://kar.kent.ac.uk/73789/.

[13] Gucin N. O.\& Berk O. S. (2015). Technology Acceptance in Health Care: An Integrative Review of Predictive Factors and Intervention Programs. 195, 1698-1704. DOI 10.1016/j.sbspro.2015.06.263.

[14] Lai P. C (2017). The Literature Review of Technology Adoption Models and Theories for the Novelty Technology, Electronic Journal of Information Systems and Technology Management, 14(1), 21-38, Retrieved 20 April, 2019, from http://www.jistem.fea.usp.br

[15] Ajzen, I., \& Fishbein, M. (1980). Understanding Attitudes and Predicting Social Behavior. Engelwood Cliffs, NJ, Prentice Hall.

[16] Greene K., (2009). Reasoned Action Theory Scope Components, New Jersey, Rutgers University Press.

[17] Sutton, S., French, D.P., Hennings, S.J. et al. Curr Psychol (2003). 22: 234. DOI.org/10.1007/s12144003-1019-1.

[18] Fishbein, M., \& Ajzen, I. (1975). Belief, Attitude, Intention, and Behavior: An Introduction to Theory and Research. Reading, MA: Addison-Wesley.

[19] Taherdoost H. (2018). A review of Technology Acceptance and Adoption Models and Theories. 22. 960-967. DOI 10.1016/j.promfg.2018.08.137.

[20] Davis, F. D. (1993). User Acceptance of Information Technology: System Characteristics, User Perceptions And Behavioral Impacts. International Journal of Man-Machine Studies, 38, 475-487. DOI:10.1006/imms.1993.1022.

[21] Lim W. M (2018). Dialectic Antidotes to Critics of the Technology Acceptance Model: Conceptual, Methodological and Replication Treatments for Behavioral Modelling in Technology-Mediated Environments, Swinburne, Australasian Journal of Information Systems

[22] Goodhue D. L \& Thompson R. L (1995). Task-Technology Fit and Individual Performance, Management Information Systems Research Center, University of Minnesota. 
International Journal of Computer Science \& Information Technology (IJCSIT) Vol 13, No 1, February 2021

[23] Venkatesh, V., \& Davis, F. D. (2000). A Theoretical Extension of The Technology Acceptance Model: Four Longitudinal Field Studies. Management Science. 46 ( 2) 186-204.

[24] Venkatesh V., Morris M. G., Davis G. B. \& Davis F. D. (2003). User Acceptance of Information Technology: Toward A Unified View, MIS Quarterly, Volume 27 (3),425-478.

[25] Taylor S \& Todd P. A. (1995). Understanding Information Technology Usage: A Test of Competing Models. The Institute for Operations Research and the Management Sciences, DOI:10.1287/isre.6.2.144.

[26] Zhou L. L., Marfo J. O., Antwi H. A., Antwi M. O., Kachie A.D. \& Wireko S. A. (2019). Assessment of the social influence and dacilitating conditions that support nurses adoption of hospital electronic information management systems (HEIMS) in Ghana using the unified theory of acceptance and use of technology (UTAUT) model. Retrieved 20 January, 2020. DOI.org/10.1186/s12911-019-0956-z.

[27] Hamzat S. \& Mabawonku I. (2018). Influence of Performance Expectancy and Facilitating Conditions on use of Digital Library by Engineering Lecturers in universities in South-west, Nigeria. Library Philosophy and Practice (e-journal).1620. from https://digitalcommons.unl.edu/libphilprac/1620

[28] Alam M. Z., Hu W., \& Gani M. O. (2019). An Empirical Analysis of the Influencing Factors of Adoption of Mobile Health Services in Bangladesh Based on Extended UTAUT Model. WHICEB 2019 Proceedings. 53 from https://aisel.aisel.org/whiceb2019/53

[29] Fayad R. \& Paper D. (2015). The Technology Acceptance Model E-Commerce Extension: A Conceptual Framework, Lebabon, Elsevier.

[30] Mahmood M. A., Gemoets L. A., \& Jacquez C. (1999). Variables Affecting Information Technology End-User Satisfaction. DOI:10.1006/ijhc.1999.0353.

\section{AUTHORS}

\section{Gilbert Busolo Lusweti}

Results-driven professional offering a progressive result driven fifteen -year career in Information Technology. A process improvement champion with a history of implementing procedures and technologies to enhance operational efficiency, value addition and quality based decision making through systematic automation and digitization efforts. Currently a MSc. Student at Jomo Kenyatta University of Agriculture and Technology, focused on Technology Adoption and Knowledge Management.

\section{Dr. Lawrence Nderu}

Experienced University Lecturer with a demonstrated history of working in the higher education industry. Skilled in Software Development, (Python, Java, C\#, $\mathrm{C}++$, R, JavaScript, Android, PHP, C++, and Databases. Strong education professional with a Doctor of Philosophy - PhD focused in Computer Science from University of Vincennes in Saint-Denis, Paris, France. Research Interest on Artificial Intelligence, Data Science and Software Development. Goal: Technology for building the resilience of communities.

\section{Dr. Kennedy Ogada}

Champion for effective and efficient Data Mining classification techniques. Experienced University Lecturer on Information Technology, Information Policy, Telecommunications Policy, and Media and Foreign Policy. PhD in Information Technology.
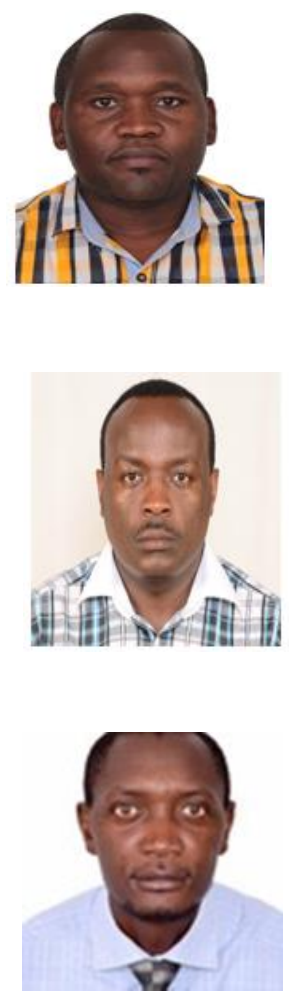